\title{
Identification of Differentially Expressed Genes in Shoot Apex of Garlic (Allium sativum L.) Using Illumina Sequencing
}

\author{
Xiu Dong Sun ${ }^{1}$, Gui Qin $\mathrm{Ma}^{1}$, Bo Cheng ${ }^{1}, \mathrm{He} \mathrm{Li}^{1} \&$ Shi Qi Liu ${ }^{1}$ \\ ${ }^{1}$ State Key Laboratory of Crop Biology, College of Horticulture Science and Engineering, Shandong \\ Agricultural University, China
}

Correspondence: Shi Qi Liu, College of Horticulture Science and Engineering, Shandong Agricultural University, Taian, Shandong 271018, China. Tel: 86-0538-8246818. E-mail: sqliu@sdau.edu.cn

Received: June 17, 2013 Accepted: July 12, 2013 Online Published: July 18, 2013

doi:10.5539/jps.v2n2p136

URL: http://dx.doi.org/10.5539/jps.v2n2p136

\begin{abstract}
Garlic is widely used as a spice throughout the world. In this study, transcriptional profilings of garlic shoot apex were performed by using the Illumina technology. A total of 45,363 significantly changed expressed transcripts were detected between the dormant and sprouting garlic shoot apex libraries. The expression of 22,836 unigenes was increased by more than 2-fold in sprouting garlic shoot apex as compared with dormant shoot apex (up-regulated unigene), and 22,526 unigenes were identified as having been down-regulated. Gene ontology (GO) annotations indicated that the differentially expressed genes were mainly played role in nucleotide binding, plastid, hydrolase activity, transferase activity, protein metabolic process, nucleic acid binding, protein binding, mitochondrion. A total of 8,725 differentially expressed genes were assigned to five Kyoto Encyclopedia of Genes and Genomes (KEGG) biochemical pathways, including metabolism, genetic information processing, organism system, cellular processes, and environmental information processing. Real-time quantitative RT-PCR (qRT-PCR) was performed to dissect shoot apex sprouting. The differential expression of genes, such as ENHYDROUS, DAG1, DAM, DTH8, indicate that they play a critical role in shoot apex sprouting. These differentially expressed genes comprise related candidates for shoot apex sprouting regulation in Allium species.
\end{abstract}

Keywords: garlic, sprouting, illumina sequencing, transcriptome profile, qRT-PCR

\section{Introduction}

Garlic (Allium sativum L.) is one of the cultivated Allium vegetables widespred the world and is widely used as a spice. Garlic is harvested in the Shandong region of China from May to June and stored to maintain a year round supply. At harvest, garlic bulbs are usually dormant (Ledesma et al., 1980). Length of the dormant period depended on both the storage conditions and the genetic background of the cultivar (Cantwell et al., 2003). During post-harvest storage, dormancy gradually diminished with the beginning of inner sprout growth. Sprouting of garlic bulbs during storage is the major factor limiting storage life, as it results in loss of dry matter, quality decreases, and onset of disease.

Abscisic acid (ABA) and Gibberlin acid (GA) plays a major regulatory part in seed dormancy and germination (Sreenivasulu et al., 2008). While ABA increases during seed maturation and dormancy, GA levels peak during seed germination and postgerminative growth. However, evidence is growth for a role of auxin during this process (Holdsworth et al., 2008). Ethylene promotes dormancy breaking through interactions with ABA signaling. Seeds of ethylene resistant 1 (etr1), ethylene insensitive 2 (ein2), and enhanced response to aba 3 (era3) mutants display enhanced dormancy and increased sensitivity to ABA (Chiwocha et al., 2005; Beaudoin et al., 2000). A number of studies utilized transcriptomic approaches to investigate seed dormancy and germination. Nearly 12,000 mRNA categories in mature dry seeds were found in barley (Hordeum vulgare L.) and Arabidopsis (Arabidopsis thaliana) (Nakabayashi et al., 2005; Sreenivasulu et al., 2008). These authors assumed that the stored mRNAs take part in de novo synthesis of protein during the early stages of germination. Global gene expression during vegetative buds dormancy maintenance and release were examined in potato (Faivre-Rampant et al., 2004; Campbell et al., 2008), and leafy spurge (Horvath et al., 2008). These studies have identified a suit of differentially expressed genes, and several of them are specifically involved in vegetative buds dormancy maintenance and sprouting. However, the molecular mechanism of dormancy maintenance and sprouting in Allium crops is poorly studied, and remains largely unknown. 
Over the past several years, RNA-sequencing (RNA-Seq) has emerged as a mighty and cost-effective tool for transcriptome analysis and this has noticeably enhanced the efficiency and velocity of gene discovery (Schuster, 2008; Ansorge, 2009). The RNA-Seq technology was revealed to have comparatively little variety between technical replicates for discovering differentially expressed genes (Marioni et al., 2008). Transcriptome analysis using Illumina sequencing approach is one of the most universal tools for gene identify, and it has been applied recently to several species that lack genomic sequence information, including sweet potato (Ipomoea batatas) (Wang et al., 2010), Eichhornia paniculata (Ness et al., 2011), alfalfa (Medicago sativa) (Yang et al., 2011), and tea (Camellia sinensis) (Shi et al., 2011).

In this study, transcripts involved in garlic shoot apex dormancy and sprouting were identified, and their putative functions were discussed. The gene expression profiles will suppiy a better comprehending of the mechanisms regulating dormancy release in Allium crops, and provide useful information for further research.

\section{Method}

\subsection{Plant Material and RNA Extraction}

Garlic bulbs (Allium sativum, cultivar Cangshan 15) were harvested from entirely mature plants grown in the field. Garlic bulbs were grown in the Province of Shan Dong, China. After harvest, the bulbs were stored at room temperature. To analyze the gene expression during sprouting, shoot apex were excised from cloves at four stages: bulbs stored for 2 weeks, 6 weeks, 10 weeks and 16 weeks. Samples were frozen in liquid nitrogen and stored at $-80{ }^{\circ} \mathrm{C}$ ahead of the RNA extraction. Total RNA was isolated using the TRIzol reagent (Invitrogen, Carlsbad, CA, USA) according to the producer's book of instructions.

\subsection{Identification of Differentially Expressed Genes}

In a previous study, two garlic Illumina libraries were constructed from tissues of dormancy and sprouting shoot apex (Sun et al., 2012). A total of 127,933 unigenes were achieved form the two libraries. A total of 47,095 unigenes had annotation in the public databases. To identify genes differently expressd between two samples, a statistical analysis of the frequency of each gene in the two cDNA libraries was developed using the method described by Audic et al. (1999). The total unigene number of the sample 1 is N1, and total unigene number of sample 2 is $\mathrm{N} 2$; gene A holds $\mathrm{x}$ unigenes in sample1 and y unigenes in sample2. The probability of gene A expressed equally between two samples can be calculated with the following formula:

$$
\begin{aligned}
& 2 \sum_{i=0}^{i=y} p(i \mid x) \\
& \text { Or } 2 \times\left(1-\sum_{i=0}^{i=y} p(i \mid x)\right) \quad\left(\operatorname{if} \sum_{i=0}^{i=y} p(i \mid x)>0.5\right) \\
& p(y \mid x)=\left(\frac{N_{2}}{N_{1}}\right)^{y} \frac{(x+y) !}{x ! y !\left(1+\frac{N_{2}}{N_{1}}\right)^{(x+y+1)}}
\end{aligned}
$$

The threshold of $\mathrm{P}$ value was estimated by false discovery rate (FDR) in multiple test and analysis. Gene expression difference was judged by using FDR $\leq 0.001$ and the absolute value of $\log 2$ Ratio $\geq 1$. Differentially expressed genes were identified by using more strict standards with little FDR and larger fold-change values. RPKM method (reads per kilobase per million reads) was used to calculate the expression of Unigene (Mortazavi et al., 2008).

\subsection{Functional Annotation and Classification}

The assembled unigenes were aligned to the NCBI non-redundant protein $(\mathrm{Nr})$ and Swiss-Prot protein databases using the BLASTX algorithm with an E-value cut-off of 10-5. The functional annotation by gene ontology terms was performed using the BLAST2GO software (Conesa et al., 2005). The COG annotation was performed using the BLASTX algorithm (E-value threshold: 10-5) against the Cluster of Orthologous Groups database. Unigenes were also compared with the sequences in the Kyoto Encyclopedia of Genes and Genomes database (Kanehisa et al. 2004) using BLASTx with an E-value threshold of 10-5.

\subsection{Quantitative Real-Time RT-PCR}

The differentially expressed genes were chosen by function of interest. First-strand cDNA was synthesized from DNase-treated RNA using Superscript II reverse transcriptase (Invitrogen). Primers were designed with Primer Premier 5.0 (Table 1). The reaction was performed in a total volume of $20 \mu \mathrm{L}$, containing $2 \mu \mathrm{l}$ of cDNA and 10 
$\mu l$ of SYBR Green Master Mix (TaKaRa) with a pair of primers. Thermal cycling was done on the Bio-Rad Sequence Detection System with the following program: $95{ }^{\circ} \mathrm{C}$ for $10 \mathrm{~s}$, then 40 cycles of $95{ }^{\circ} \mathrm{C}$ for $15 \mathrm{~s}$, and $60{ }^{\circ} \mathrm{C}$ for $30 \mathrm{~s}$. Triplicates of each reaction were performed, and the results were expressed relative to the expression levels of actin in each sample by using the $2^{\Delta \Delta \mathrm{CT}}$ method (Livaka \& Schmittgen, 2001).

Table 1. Sequences of primers used for qRT-PCR

\begin{tabular}{lll}
\hline Gene ID & Forward primer & Reverse primer \\
\hline DAG1 & CAGTATCTCCTTCTTCCGCAGC & TGGAAAACCCAAGTTCAAGTCA \\
ENHYDROUS & CTCCACAGAAGAGGGCACAACT & TGAGCACAAGTAGGTTCAGGACA \\
DAM & CTTTGTGATGCTGAAGTTGAC & GCTGCTCCGACCTCACTATT \\
DTH8 & ATGCGTGTCCGAGTTCATAAGC & GGGTCGTCATAGCCCACAGC \\
DREB2A & GTCACCAGTCTAATCAGCCAGG & ATCAACACCGTCTCCAACCAG \\
CHOTTO1 & AGAACAGTGTCAAGCCCCCAAT & AGCACAGGTTGACTGGGAGGTA \\
Hdzip & TTTTCCACTCCTCCACCTCTAAT & TTTCGTAAACCTTTTGCTTGCTA \\
MBF1C & ATGACTAATACGCCTGCCCTGA & GTTTTGGCTAAGATGGAGAAGGTT \\
CCD48 & ATTCAACGCTTCTCATTCCTCC & GGTCCGACTTGGTGATGTGGT \\
ARF6 & AAAATCCAGGGGAGGAAACACT & GTAAGACTTTGACTGCGAGCGA \\
EF2 & CACCCCAAAGTCTCTCCATCA & ATGAACTCCTGGGCGATGTAAT \\
TCP4 & GGACTCGCTTCTTTGAATGGAT & CTTCTTCGTTGGAGATGGTGCT \\
ACTIN & TCCTAACCGAGCGAGGCTACAT & GGAAAAGCACTTCTGGGCACC \\
\hline
\end{tabular}

\section{Results and Discussion}

\subsection{Identification of Differentially Expressed Genes}

The putative differentially expressed unigenes between two samples were identified by an algorithm developed by Audic et al. (Audic \& Claverie, 1997). A total of 45,363 significantly changed expressed unigenes were detected between the dormant and sprouting garlic shoot apex libraries (Figure 1). Of these, 34,906 unigenes showed $>5$-fold changes in expression level, and 26,410 unigenes showed $>10$-fold changes in expression. The expression of 22,836 unigenes was increased by more than 2 -fold in sprouting garlic shoot apex as compared with dormant shoot apex (up-regulated unigene, Figure 1), and 22,526 unigenes were identified as having been down-regulated. Of these differentially expressed unigenes, 7,784 unigenes were only expressed in sprouting shoot apex while 7,975 unigenes were only expressed in dormant shoot apex. 


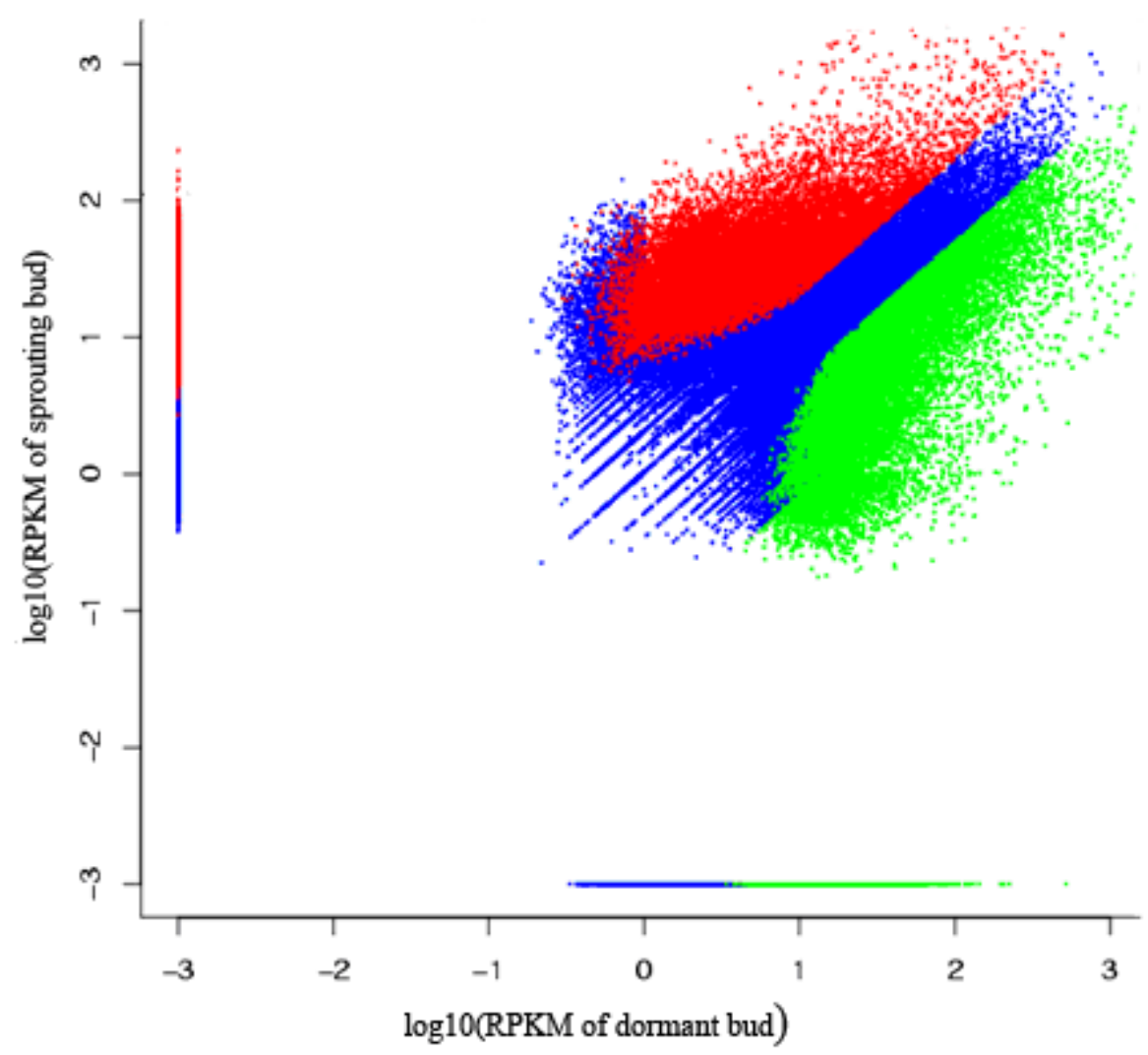

Figure 1. Gene expression levels of dormant garlic shoot apex and sprouting garlic shoot apex

The differentially expressed genes are revealed in red and green. Genes without expression changes are revealed in blue. RPKM: Reads Per kb per Million reads. FDR: false discovery rate. We used "FDR $\leq 0.001$ and the absolute value of $\log 2$ Ratio $\geq 1$ " as the threshold to judge the significance of gene expression difference. Y axes display the observed $\log 10$ ratios of RPKM of sprouting bud. X axes display the observed $\log 10$ ratios of RPKM of dormant bud.

\subsection{Functional Annotation of Differentially Expressed Genes}

All differentially expressed unigenes were compared with the sequences in public databases, including the NCBI non-redundant protein (Nr) database, the NCBI Clusters of Orthologous Groups (COGs) database, the Swiss-Prot protein database, and the Kyoto Encyclopedia of Genes and Genomes database (KEGG) using BLASTx algorithm with an E value threshold of $10^{-5}$. A total of 21,044 unigenes had significant hits (E-value $<$ $10^{-5}$ ) to the sequences in the five databases. A total of 20,549 unigenes had significant hits (E-value $<10^{-5}$ ) to the sequences in the $\mathrm{Nr}$ database. Gene Ontology $(\mathrm{GO})$ is an international standardized gene functional classification system that provides a standardized vocabulary that is used to assign function to uncharacterized sequences. We used GO analysis to classify the functions of differentially expressed genes. Putative functions were assigned to 10,840 unique sequences involved in the categories of biological process, cellular component and molecular function (Figure 2). The main functional groups of up-regulated genes are related to nucleotide binding, plastid, hydrolase activity, transferase activity, protein metabolic process, nucleic acid binding, protein binding, mitochondrion, while the main functional groups of down-regulated genes are related to plastid, mitochondrion, transferase activity, protein metabolic process, nucleotide binding, nucleic acid binding, protein binding, ion binding. The number of "genes" up-regulated are much more than the ones down-regulated. This event appears to operate in a coordinated fashion with the establishment of the full metabolic profile, and the biogenesis of organelles in the sprouting garlic bud. 


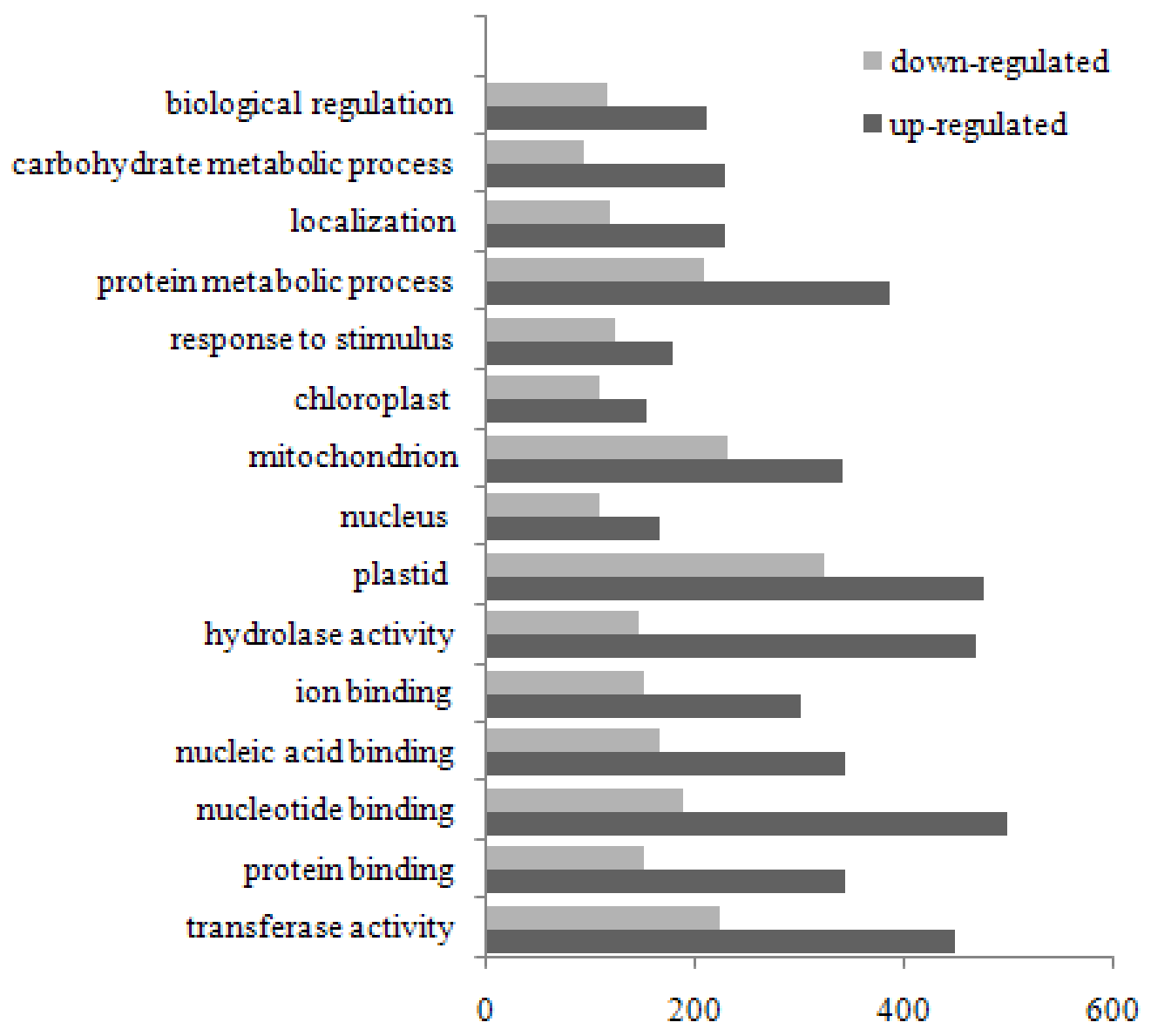

Figure 2. Gene ontology classification of assembled unigenes

$\mathrm{Y}$ axes display the categories of biological process, cellular component and molecular function. $\mathrm{X}$ axes display the number of genes.

The assembled unigenes were assigned to the biochemical pathways described in KEGG based on their EC numbers. Pathway-based analyses help to understand the biological function of genes further. A total of 9,704 differentially expressed genes demonstrated sequence similarities to the genes in the KEGG database, representing 6,321 up-regulated and 3,383 down-regulated transcripts (Additional file 1). These differentially expressed genes were assigned to five main KEGG biochemical pathways, including metabolism $(4,624$ unigenes), genetic information processing $(2,976)$, organism system (704), cellular processes (421), and environmental information processing (170) (Table 2). Those pathways related to metabolic pathways were the largest group, with a majority of the proteins involved in biosynthesis of secondary metabolites $(1,058)$, carbohydrate metabolism (945), energy metabolism (568), amino acid metabolism (511), lipid metabolism (477), and Nucleotide Metabolism (372). The second largest group comprised genetic information processing, including those genes involved in transcription (978), folding, sorting and degradation (541), translation (357). The third largest group was the organismal systems, most of which were associated with environmental adaptation (666). Pathways related to cellular processes and environmental information processing were also well represented by the unigenes from Allium sativum $\mathrm{L}$. 
Table 2. Mapping of Allium sativum differentially expressed genes to KEGG biochemical pathways

\begin{tabular}{|c|c|c|c|}
\hline \multirow[b]{2}{*}{ KEGG categories } & \multicolumn{3}{|c|}{ Number of unigenes } \\
\hline & Total & Up-regulated & Down-regulated \\
\hline Metabolism & 4624 & 3019 & 1605 \\
\hline Amino Acid Metabolism & 511 & 329 & 182 \\
\hline Biosynthesis of Secondary Metabolites & 1058 & 603 & 455 \\
\hline Carbohydrate Metabolism & 945 & 678 & 267 \\
\hline Energy Metabolism & 568 & 408 & 160 \\
\hline Glycan Biosynthesis and Metabolism & 153 & 121 & 32 \\
\hline Lipid Metabolism & 477 & 302 & 175 \\
\hline Metabolism of Cofactors and Vitamins & 235 & 142 & 93 \\
\hline Metabolism of Other Amino Acids & 244 & 141 & 103 \\
\hline Nucleotide Metabolism & 372 & 274 & 98 \\
\hline Xenobiotic Biodegradation and Metabolism & 61 & 21 & 40 \\
\hline Genetic Information Processing & 2976 & 1938 & 1038 \\
\hline Folding, Sorting, and Degradation & 541 & 357 & 184 \\
\hline Replication and Repair & 264 & 174 & 90 \\
\hline Transcription & 978 & 637 & 341 \\
\hline Translation & 357 & 235 & 122 \\
\hline Environmental Information Processing & 170 & 122 & 48 \\
\hline Membrane Transport & 95 & 76 & 19 \\
\hline Signal Transduction & 75 & 46 & 29 \\
\hline Cellular Processes & 421 & 281 & 140 \\
\hline Transport and Catabolism & 421 & 281 & 140 \\
\hline Organismal Systems & 704 & 432 & 272 \\
\hline Environmental Adaptation & 666 & 413 & 253 \\
\hline Immune System & 38 & 19 & 19 \\
\hline
\end{tabular}

Functional analysis of the up-regulated genes revealed that a large proportion of them are enzymes involved in carbohydrate metabolism, such as ascorbate oxidase, beta-galactosidase, biotin carboxylase, endoglucanase, enolase, glyceraldehyde 3-phosphate dehydrogenase, pyruvate kinase, sucrose synthase (additional file 1). Similar results were also observed in the germination of barley seeds (Zhang et al., 2004). An increase in the expression of genes belonging to energy metabolism was observed at the stage of shoot apex sprouting. This group was mainly comprised of genes involved in photosystem I and II proteins, ribulose biphosphate carboxylase, plastocyanin, and ATP synthase. Accumulation of genes which are involved in energy production was associated with bud burst in sessile oak (Quercus petraea) (Derory et al., 2006). These results indicated that energy metabolism is one of the most important factors associated with garlic shoot apex sprouting. Among those up-regulated genes, many were involved in amino acid metabolism, such as methionine synthase, adenosylhomocysteinase, glutamate synthase, leucyl synthetase, glycine dehydrogenase, arginine decarboxylase, suggesting an increase in protein synthesis essential for bud sprouting. Changes in the expression of genes participated in amino acid metabolism have also been reported during barley germination (Wilson et al., 2005). Several genes (methionine synthase and adenosylhomocysteinase) encoding enzymes participated in methionine biosynthesis and regeneration pathways, are discovered to be actively transcribed in germinating sugar beet seeds (Pestsova et al., 2008). In Arabidopsis, methionine and/or its derivatives was also play important roles in promoting germination and seedling growth (Gallardo et al., 2002).

In the sprouting library, genes involved in transcription and translation were relatively more abundant. Examples 
include ribosomal proteins, transcription initiation factor, DNA-directed RNA polymerase, pre-mRNA-processing factor, splicing factor. This finding emphasizes a central role of protein biosynthesis during bud sprouting. A prevailing number of transcripts abundant in sprouting bud encode eukaryotic elongation factors. This included EF2 which has been shown to be important for seed germination in Norway maple (Pawłowski, 2009). Changes in the expression of EF1 have been similarly reported during germination in Norway maple seeds (Twardowski \& Szczotka, 1989). EF-Tu is involved in the buildup of the photosynthetic system during seeds germination (Gallardo et al., 2001). The increase of elongation factors during germination implies that they may take part in the mechanism of bud dormancy breaking, where they are in charge of cell division and protein synthesis in meristematic tissues.

Genes involved in membrane transport were up-regulated during the bud sprouting. This group was comprised of genes encoding $\mathrm{ABC}$ transporter. PED3, a peroxisomal $\mathrm{ABC}$ transporter, promotes seed germination by inducing pectin degradation in Arabidopsis thaliana (Kanai et al., 2010). Plant ATP-binding cassette (ABC) proteins, the majority of which are transporters, are one of the largest known superfamilies. ABC transporters are involved in lipid catabolism, xenobiotic detoxification, formation of $\mathrm{Fe} / \mathrm{S}$ clusters, chlorophyll biosynthesis, ion fluxes, polar auxin transport, and stomatal function (Martinoia et al., 2002). ABC transporters are also takes part in cell elongation processes (Marin et al., 2006). Therefore, ABC transporters may play important role in plant developmental and growth processes, and the increase in $\mathrm{ABC}$ transporter gene expression corresponds to the fact that plant tissues are at growing during the sprouting period.

Genes involved in cell division and growth exhibited increased expression in non-dormant tissue. This group was comprised of genes encoding actin, tubulin, cyclin and cyclin dependent kinase. Actin, an essential component of the cytoskeleton, is critical for differentiation, cell expansion, and cell wall deposition (Wasteneys \& Galway, 2003). In Arabidopsis, ACT7 is highly expressed in young seedlings (McDowell et al., 1996). From previous studies it is known that de novo synthesis and accumulation of beta-tubulins is associated with seed dormancy breaking and germination in several species such as Arabidopsis (Chibani et al., 2006), tomato (Castro et al., 2000) and Norway maple (Pawłowski et al., 2004). $\beta$-Tubulin has been suggested to be a genetic marker for dormancy status in tree buds (Hedley et al., 2010), and is induced in expression during dormancy release in buds of woody perennial species, including blackcurrant Malus and Rosa (Bergervoet et al., 1999) and poplar (Rohde et al., 2008). D-type cyclins promote seed germination due to its division activity in the root apex in Arabidopsis (Masubelele et al., 2005). Altogether, these results demonstrate that genes involved in cell division and growth are the important determinant of completion of dormancy breaking and growth initiation.

A prevailing number of transcripts encoding heat shock proteins (HSPs) were abundant both in dormant and sprouting buds. Small heat-shock proteins (sHSPs) have also been shown to accumulate during seed maturation in several species, and a role for these proteins in desiccation tolerance, dormancy has been hypothesized (Wehmeyer et al., 1996). The 70-kD heat shock proteins (Hsp70s) involved in a variety of cellular processes including protein folding, assembly and degradation (Bukau et al. 2006). Several HSP70s were identified in Norway maple seed, which were associated with dormancy breaking (Pawłowski, 2009). The results of this study indicated that HSPs are required during garlic shoot apex dormancy maintenance and sprouting to maintain the proper folding of other proteins. A striking finding was the high percentage of oxygen stress related genes such as catalase, superoxide dismutase, glutathione S-transferase and glutathione reductase present in both libraries. Several studies indicate that levels of antioxidant enzymes increase during seed dehydration (Chen et al., 2010). Antioxidant enzymes, induced in dormant garlic shoot apex, may play a role in protecting shoot apex from desiccation damage by exposure to reactive oxygen species. Furthermore, other studies report that seed and bud dormancy release coincides with an up-regulation of the antioxidant system (Hedley et al., 2010). In sunflower (Helianthus annuus L.) seeds, ROS caused lipid peroxidation, carbonylation of a specific subset of proteins and mRNA oxidation which were associated with seed dormancy release (Bazin et al., 2011). The high level of expression of antioxidant enzymes in sprout garlic shoot apex indicate these enzymes play a role in decreasing the level of ROS after it has acted as a chemical signal to induce dormancy release. A large proportion of transcripts abundant both in dormant and sprouting buds encode ribosomal proteins, transcription initiation factor, DNA-directed RNA polymerase, pre-mRNA-processing factor, splicing factor. This finding emphasizes a central role of protein biosynthesis during both shoot apex dormancy maintenance and sprouting.

\subsection{Hormone Related Genes}

ABA levels are correlated with dormancy in vegetative reproductive organs and tend to drop during dormancy release (Yamazaki et al., 1999). Our expression profiling studies show that key ABA biosynthetic transcripts 9-cis-epoxycarotenoid dioxygenase (NCED) and zeaxanthin epoxidase (ZEP) are expressed at high levels in dormant shoot apex as compared with sprouting shoot apex (Additional file 2). Our results also provide hints that 
ABA signaling network genes such as $\mathrm{ABA}$ receptor protein, $\mathrm{ABA}$-responsive element binding protein, ABA-insensitive protein 5 (ABI5), and protein phosphatase $2 \mathrm{C}$ are expressed to a higher extent in the garlic shoot apex during dormancy than during sprouting. In this study, a set of putative ABA-regulated genes were down-regulated during the transition from dormancy to sprouting, including Serine/threonine-protein kinase, abscisic stress-ripening protein 1, possibly indicating changing ABA levels in the shoot apex. Thomas (1969) found that gibberellin activities decreased before sprouting, but that there was an increase in gibberellin and auxin activities as soon as sprouting had begun in onion (Allium cepa). Our expression profiling studies display that key GA biosynthetic transcripts, gibberellin 2 oxidase $\left(\mathrm{GA}_{2}\right)$ and gibberellin 20 oxidase $\left(\mathrm{GA}_{20}\right)$, are expressed at high levels in sprouting shoot apex as compared with dormant shoot apex. Our results also show that GA signaling network genes, GA receptor protein (GID1L2) are expressed to a higher extent in the garlic shoot apex during sprouting than during dormancy.Numerous auxin response factors (ARF), auxin transport proteins are activated preferentially in the sprouting garlic shoot apex. Perturbing auxin transport proteins leads to a reduction in meristematic activity in several plants (Morris et al., 2005; Blilou et al., 2005). Our results also show that ethylene signaling network genes such as ethylene insensitive 2 (EIN2), and ethylene receptor 2 are expressed to a higher extent in the garlic shoot apex during sprouting. The preferential expression of these genes in the sprouting shoot apex suggests an important role in cell expansion during shoot apex sprouting.

\subsection{Transcription Patterns of Candidate Genes}

A group of genes were chosen to study the expression patterns in detail at the four stages by qRT-PCR (Figure 3). They were selected based on their putative function in dormancy and sprouting determination, and on our research interest in epigenetic regulation in garlic. The PCR products were sequenced, and all the products were specific amplification. In both libraries, we found a large number of unigenes having a Zn-finger DNA-binding motif. The expressions of zinc finger gene Dof affecting germination 1 (DAG1) were down-regulated during garlic shoot apex sprouting, while the $\mathrm{C} 2 \mathrm{H} 2$ type zinc finger gene ENHYDROUS was up-regulated, indicating that these zinc finger genes play positive or negative roles during shoot apex dormancy transition.. DAG1 has been reported to be involved in the control of seed dormancy in Arabidopsis thaliana (Papi et al., 2000). ENHYDROUS has been reported to promotes seed germination in Arabidopsis thaliana (Feurtado et al., 2011). A cluster of $S V P$-like genes, named dormancy associated MADS-box (DAM) genes, had shown to be important components in dormancy transition in several species. In Arabidopsis, SVP acts as a direct repressor of flowering (Yant et al., 2009). In this study, a homologue of DAM transcription factor was down-regulated during sprouting. A putative homologue of the nuclear transcription factor DTH8 was down-regulated during garlic shoot apex sprouting. DTH8 has been reported to play a role in suppresses flowering in Rice (Wei et al., 2010). Horvath (Horvath, 2009) has hypothesized that similar mechanisms regulate bud flowering and dormancy. The result of this study indicates DAM and DTH8 play a role in regulating garlic shoot apex dormancy. The expression level of the dehydration-responsive element-binding protein 2A (DREB2A) had a decreasing trend, reaching a minimum after shoot apex sprouting. A putative double APETALA2 repeat transcription factor CHOTTO1 was down-regulated during sprouting. CHOTTO1 is involved in abscisic acid-mediated repression of gibberellin biosynthesis during seed germination in Arabidopsis. Other genes such as multiprotein-bridging factor 1C (MBF1C), Homeodomain leucine zipper (HDZIP) were first induced to a high expression level and then decreased, indicating that they might play major roles in specific dormancy stages. A subset of genes had an increased expression during dormancy transition. The putative cell division control protein (CDC48), TCP transcription factor 4 (TCP4) and auxin response factor 6 (ARF6) were included in this group. In potato, the increased expression of auxin response factor (ARF6) was associated with dormancy release (Faivre-Rampant et al. 2004). The expression level of eukaryotic elongation factor 2 (EF2) was up-regulated during sprouting.

\subsection{Conclusion}

This study has confirmed the usefulness of Illumina sequencing approach in identifying genes related to shoot apex sprouting, and has provided new insights in the understanding of gene expression during shoot apex sprouting. The substantial amount of transcripts obtained in the present study provides a useful resource to investigate the molecular bases of shoot apex dormancy and sprouting. Several candidate genes that are most likely involved in shoot apex dormancy and sprouting have also been isolated and their differential expression validated by qRT-PCR. Further functional analysis of the differentially expressed genes will provide deeper insight into the regulation garlic shoot apex sprouting. 
DAG1
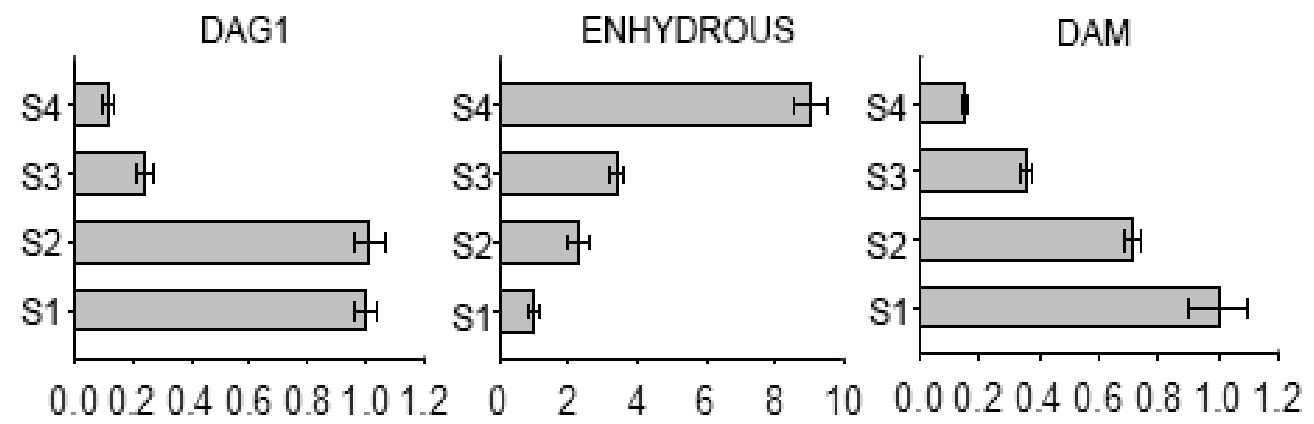

DTH8
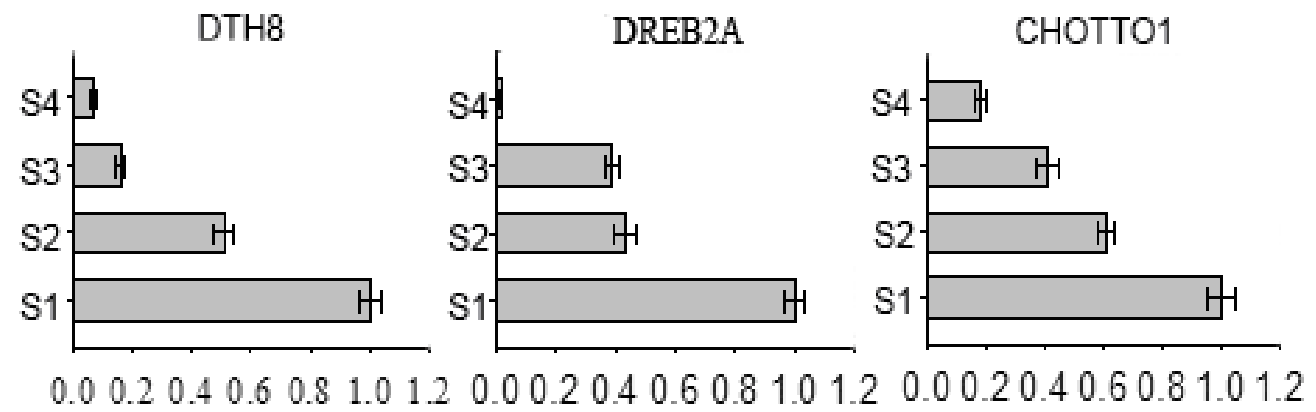

$0.00 .20 .40 .60 .81 .01 .2 \quad 0.00 .20 .40 .60 .81 .01 .20 .00 .20 .40 .60 .81 .01 .2$

HDZIP
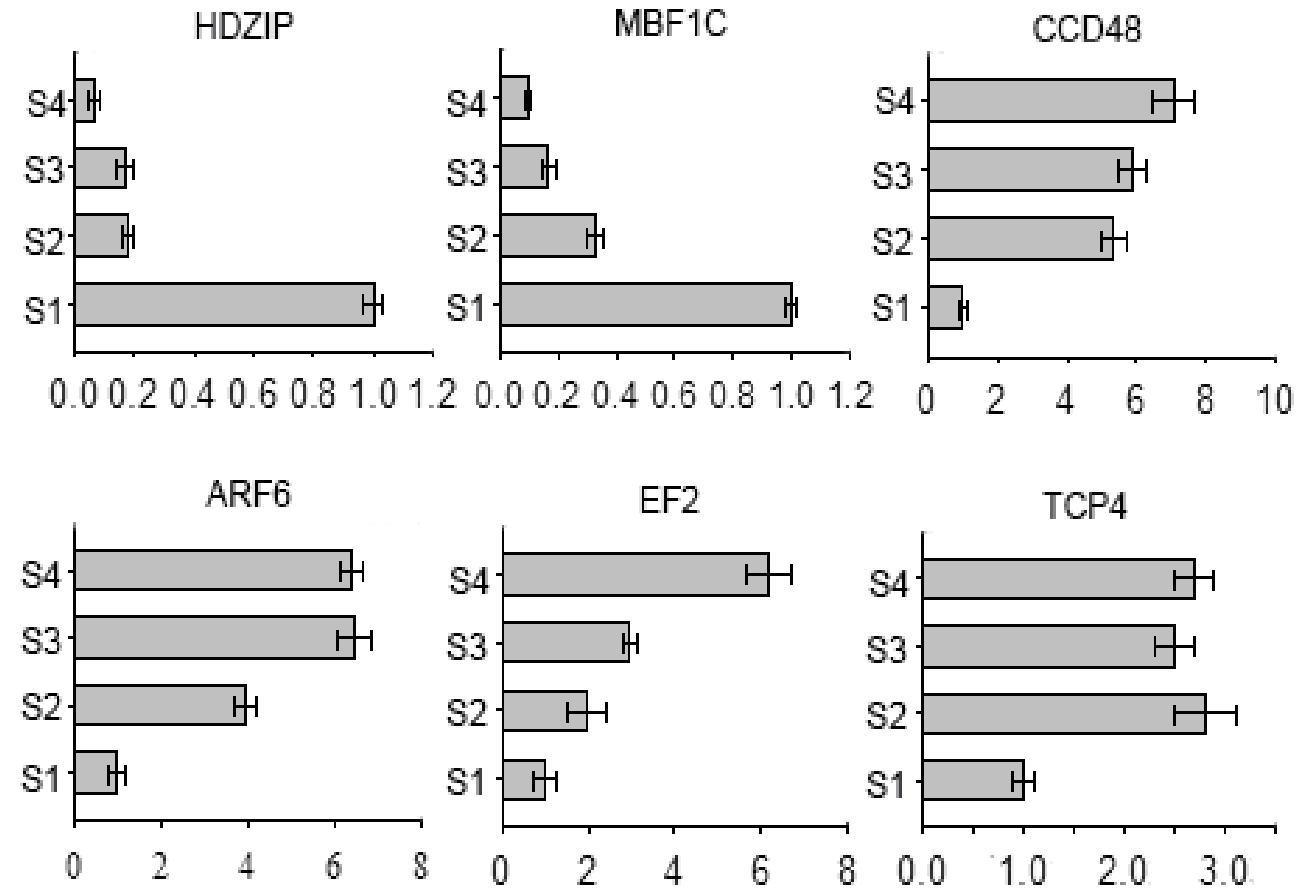

Figure 3. The expression profiles of selected genes

Relative expression of the 12 genes detected by qRT-PCR in different stored stages of the garlic shoot apex. S1, S2, S3 and S4 represent the shoot apex of garlic bulb stored for 2 weeks, 6 weeks, 10 weeks and 16 weeks, respectively. The transcript levels were normalized to that of actin, and the level of each gene in the first stage (S1) was set at 1.0. Error bars represent the SE for three independent experiments. y axes display different stored stages of the garlic shoot apex. $\mathrm{x}$ axes display relative expression levels of each gene.

\section{Acknowledgements}

This study was supported by the Chinese National Department Public Benefit Research Foundation (No. 


\section{8)}

\section{References}

Ansorge, W. J. (2009). Next-generation DNA sequencing techniques. New Biotechnology, 25, 195-203. http://dx.doi.org/10.1016/j.nbt.2008.12.009

Audic, S., \& Claverie, J. M. (1997). The Significance of Digital Gene Expression Profiles. Genome Res, 7 , 986-995.

Bazin, J., Langlade, N., Vincourt, P., Arribat, S., Balzergue, S., El-Maarouf-Bouteau, H., \& Bailly, C. (2011). Targeted mRNA Oxidation Regulates Sunflower Seed Dormancy Alleviation during Dry After-Ripening. Plant Cell, 23, 2196-2208. http://dx.doi.org/10.1105/tpc.111.086694

Beaudoin, N., Serizet, C., Gosti, F., \& Giraudat, J. (2000). Interactions between abscisic acid and ethylene signaling cascades. The Plant Cell, 12(7), 1103-1115. http://dx.doi.org/10.1105/tpc.12.7.1103

Bergervoet, J. H. W., Jing, H. C., Hout, J. W. E. V. D., Castro, R. D. D., Kunneman, B. P. A. M., Bino, R. J., \& Groot, S. P. C. (1999). Expression of beta-tubulin during dormancy induction and release in apical and axillary buds of five woody species. Physiol Plantarum, 106, 238-245. http//dx.doi.org/10.1034/j.1399-3054.1999.106214.x

Bukau, B., Weissman, J., \& Horwich, A. (2006). Molecular Chaperones and Protein Quality Control. Cell, 125, 443-451. http://dx.doi.org/10.1016/j.cell.2006.04.014

Cantwell M, Hong G, Kang, J., \& Nie, X. (2003). Controlled atmospheres retard sprout growth, affect compositional changes, and maintain visual quality attributes of garlic. Acta Hortic, 600, 791-794.

Castro, R. D. D., Lammeren, A. A. M. V., Steven, P. C., Groot, R. J. B., Hilhorst, H. W. M. (2000). Cell Division and Subsequent Radicle Protrusion in Tomato Seeds Are Inhibited by Osmotic Stress But DNA Synthesis and Formation of Microtubular Cytoskeleton Are Not. Plant Physiol, 122, 327-326. http://dx.doi.org/10.1104/pp.122.2.327

Chen, Q., Yang, L., Ahmad, P., Wan, X., \& Hu, X. (2010). Proteomic profiling and redox status alteration of recalcitrant tea (Camellia sinensis) seed in response to desiccation. Planta, 233, 583-592. $\mathrm{http} / / \mathrm{dx}$.doi.org/10.1007/s00425-010-1322-7

Chibani, K., Ali-Rachedi, S., Job, C., Job, D., Jullien, M., Grappin, P. (2006). Proteomic Analysis of Seed Dormancy in Arabidopsis. Plant Physiol, 142, 1493-1510. http://dx.doi.org/10.1104/pp.106.087452

Chiwocha, S. D., Cutler, A. J., Abrams, S. R., Ambrose, S. J., Yang, J., Ross, A. R., \& Kermode, A. R. (2005). The etr1-2 mutation in Arabidopsis thaliana affects the abscisic acid, auxin, cytokinin and gibberellin metabolic pathways during maintenance of seed dormancy, moist-chilling and germination. The Plant Journal, 42(1), 35-48. http://dx.doi.org/10.1111/j.1365-313X.2005.02359.x

Conesa, A., Götz, S., García-Gómez, J. M., Terol, J., Talón, M., \& Robles, M. (2005). Blast2GO: a universal tool for annotation, visualization and analysis in functional genomics research. Bioinformatics, 21, 3674-3676. http//dx.doi.org/10.1093/bioinformatics/bti610

Derory, J., Léger, P., Garcia, V., Schaeffer, J., Hauser, M. T., Salin, F., Luschnig, C., Plomion, C., Glössl, J., \& Kremer, A. (2006). Transcriptome analysis of bud burst in sessile oak (Quercus petraea). New Phytol, 170, 723-738. http//dx.doi.org/10.1111/j.1469-8137.2006.01721.x

Faivre-Rampant, O., Cardle, L., Marshall, D., Viola, R., \& Taylor, M. A. (2004). Changes in gene expression during meristem activation processes in Solanum tuberosum with a focus on the regulation of an auxin response factor gene. $J \operatorname{Exp}$ Bot, 55, 613-622. http//dx.doi.org/10.1093/jxb/erh075

Feurtado, J. A., Huang, D., Wicki-Stordeur, L., Hemstock, L. E., Potentier, M. S., Tsang, E. W., \& Cutler, A. J. (2011). The Arabidopsis C2H2 Zinc Finger INDETERMINATE DOMAIN1/ENHYDROUS Promotes the Transition to Germination by Regulating Light and Hormonal Signaling during Seed Maturation. Plant Cell, 23, 1772-1794. http://dx.doi.org/10.1105/tpc.111.085134

Gallardo, K., Job, C., Groot, S. P. C., Puype, M., Demol, H., Vandekerckhove, J., \& Job, D. (2001). Proteomic Analysis of Arabidopsis Seed Germination and Priming. Plant Physiol, 126, 835-848. http://dx.doi.org/10.1104/pp.126.2.835

Gallardo, K., Job, C., Groot, S. P. C., Puype, M., Demol, H., Vandekerckhove, J., \& Job, D. (2002). Importance of methionine biosynthesis for Arabidopsis seed germination and seedling growth. Physiol Plantarum, 116, 
238-247. http//dx.doi.org/10.1034/j.1399-3054.2002.1160214.x

Hedley, P. E., Russell, J. R., Jorgensen, L., Gordon, S., Morris, J. A., Hackett, C. A., Cardle, L., \& Brennan, R. (2010). Candidate genes associated with bud dormancy release in blackcurrant (Ribes nigrum L.). BMC Plant Biol, 10, 202-214. http//dx.doi.org/10.1186/1471-2229-10-202

Holdsworth, M. J., Finch-Savage, W. E., Grappin, P., \& Job, D. (2008). Post-genomics dissection of seed dormancy and germination. Trends Plant Sci, 13, 7-13. http://dx.doi.org/10.1016/j.tplants.2007.11.002

Horvath, D. (2009). Common mechanisms regulate flowering and dormancy. Plant Sci, 177, 523-531. http://dx.doi.org/10.1016/j.plantsci.2009.09.002

Horvath, D. P., Chao, W. S., Suttle, J. C., Thimmapuram, J., \& Anderson, J. V. (2008). Transcriptome analysis identifies novel responses and potential regulatory genes involved in seasonal dormancy transitions of leafy spurge (Euphorbia esula L.). BMC Genomics, 9, 536. http//dx.doi.org/10.1186/1471-2164-9-536

Kanai, M., Nishimura, M., \& Hayashi, M. (2010). A peroxisomal ABC transporter promotes seed germination by inducing pectin degradation under the control of ABI5. Plant J, 62, 936-947. http//dx.doi.org/10.1111/j.1365-313X.2010.04205.x

Kanehisa, M., Goto, S., Kawashima, S., Okuno, Y., \& Hattori, M. (2004). The KEGG resource for deciphering the genome. Nucleic Acids Res, 32, D277-D280. http//dx.doi.org/10.1093/nar/gkh063

Ledesma, A., Reale, M. I., Racca, R., \& Burba, J. L. (1980). Effect of low temperatures and preplanting storage time on garlic clonal type Rosado Paraguayo growth. Phyton (Argentina), 39, 37-48.

Livaka, K. J., \& Schmittgen, T. D. (2001). Analysis of Relative Gene Expression Data Using Real-Time Quantitative PCR and the $2^{-\Delta \Delta C T}$ Method. Methods, 25, 402-408. http://dx.doi.org/10.1006/meth.2001.1262

Marin, E., Divol, F., Bechtold, N., Vavasseur, A., Nussaume, L., \& Forestier, C. (2006). Molecular characterization of three Arabidopsis soluble ABC proteins which expression is induced by sugars. Plant Sci, 171, 84-90. http://dx.doi.org/10.1016/j.plantsci.2006.02.014

Marioni, J. C., Mason, C. E., Mane, S. M., Stephens, M., \& Gilad, Y. (2008). RNA-seq: An assessment of technical reproducibility and comparison with gene expression arrays. Genome Res, 18, 1509-1517. http//dx.doi.org/10.1101/gr.079558.108

Martinoia, E., Klein, M., Geisler, M., Bovet, L., Forestier, C., Kolukisaoglu, Ü., ... Schulz, B. (2002). Multifunctionality of plant $\mathrm{ABC}$ transporters-more than just detoxifiers. Planta, 214, 345-355. http//dx.doi.org/10.1007/s004250100661

Masubelele, N. H., Dewitte, W., Menges, M., Maughan, S., Collins, C., Huntley, R., ... Murray, J. A. H. (2005). D-type cyclins activate division in the root apex to promote seed germination in Arabidopsis. PNAS, 102, 15694-15699. http//dx.doi.org/10.1073/pnas.0507581102

McDowell, J. M., An, Y., Huang, S., McKinney, E. C., \& Meagher, R. B. (1996). The Arabidopsis ACT7 actin gene is expressed in rapidly developing tissues and responds to several external stimuli. Plant Physiol, 111, 699-711. http://dx.doi.org/10.1104/pp.111.3.699

Mortazavi, A., Williams, B. A., McCue, K., Schaeffer, L., \& Wold, B. (2008). Mapping and quantifying mammalian transcriptomes by RNA-Seq. Nature methods, 5(7), 621-628. http//dx.doi.org/10.1038/nmeth.1226

Nakabayashi, K., Okamoto, M., Koshiba, T., Kamiya, Y., \& Nambara, E. (2005). Genome-wide profiling of stored mRNA in Arabidopsis thaliana seed germination: epigenetic and genetic regulation of transcription in seed. Plant J., 41, 697-709. http//dx.doi.org/10.1111/j.1365-313X.2005.02337.x

Ness, R. W., Siol, M., \& Barrett, S. C. (2011). De novo sequence assembly and characterization of the floral transcriptome in cross- and self-fertilizing plants. BMC Genomics, 12, 298. http//dx.doi.org/10.1186/1471-2164-12-298

Papi, M., Sabatini, S., Bouchez, D., Camilleri, C., Costantino, P., \& Vittorioso, P. (2000). Identification and disruption of an Arabidopsis zinc finger gene controlling seed germination. Gene Dev, 14, 28-33. http//dx.doi.org/10.1101/gad.14.1.28 Genes \& Dev. 2000. 14: 28-33

Pawłowski, T. A. (2009). Proteome analysis of Norway maple (Acer platanoides L.) seeds dormancy breaking and germination: influence of abscisic and gibberellic acids. BMC Plant Biol, 9, 48. http//dx.doi.org/10.1186/1471-2229-9-48 
Pawłowski, T. A., Bergervoet, J. H. W., Bino, R. J., \& Groot, S. P. C. (2004). Cell Cycle Activity and $\beta$-Tubulin Accumulation During Dormancy Breaking of Acer platanoides L. seeds. Biologia Plantarum, 48, 211-218. http//dx.doi.org/10.1023/B:BIOP.0000033447.27149.85

Pestsova, E., Meinhard, J., Menze, A., Fischer, U., Windhövel, A., \& Westhoff, P. (2008). Transcript profiles uncover temporal and stress-induced changes of metabolic pathways in germinating sugar beet seeds. $B M C$ Plant Biol, 8, 122. http//dx.doi.org/10.1186/1471-2229-8-122

Rohde, A., Ruttink, T., Hostyn, V., Sterck, L., Driessche, K. V., \& Boerjan, W. (2008). Gene expression during the induction, maintenance, and release of dormancy in apical buds of poplar. $J \operatorname{Exp}$ Bot, 58, 4047-4060. http//dx.doi.org/10.1093/jxb/erm261

Schuster, S. C. (2008). Next-generation sequencing transforms today's biologyNature Methods. Nature Methods, 5, 16-18. http//dx.doi.org/ doi:10.1038/nmeth1156

Shi, C. Y., Yang, H., Wei, C. L., Yu, O., Zhang, Z. Z., Jiang, C. J., ... Wan, X. C. (2011). Deep sequencing of the Camellia sinensis transcriptome revealed candidate genes for major metabolic pathways of tea-specific compounds. BMC Genomics, 12, 131. http//dx.doi.org/10.1186/1471-2164-12-131

Sreenivasulu, N., Usadel, B., Winter, A., Radchuk, V., Scholz, U., Stein, N., ... Wobus, U. (2008). Barley Grain Maturation and Germination: Metabolic Pathway and Regulatory Network Commonalities and Differences Highlighted by New MapMan/PageMan Profiling Tools. Plant Physiol, 146, 1738-1758. http://dx.doi.org/10.1104/pp.107.111781

Sun, X., Zhou, S., Meng, F., \& Liu, S. (2012). De novo assembly and characterization of the garlic (Allium sativum) bud transcriptome by Illumina sequencing. Plant cell reports, 31(10), 1823-1828. http//dx.doi.org/10.1007/s00299-012-1295-z

Thomas, T. H. (1969). The Role of Growth Substances in the Regulation of Onion Bulb Dormancy. J Exp Bot, 20, 124-137. http//dx.doi.org/10.1093/jxb/20.1.124

Twardowski, T., \& Szczotka, Z. (1989). The influence of selected polyamines on elongation binding factor 1 activity during the stratification of Norway maple seeds. J. Plant Physiol, 134, 32-36. http://dx.doi.org/10.1016/S0176-1617(89)80198-1

Wang, Z., Fang, B., Chen, J., Zhang, X., Luo, Z., Huang, L., Chen, X., \& Li, Y. (2010). De novo assembly and characterization of root transcriptome using Illumina paired-end sequencing and development of cSSR $\begin{array}{llllll}\text { markers in sweetpotato (Ipomoea batatas). BMC Genomics, } 11, & 726 .\end{array}$ http//dx.doi.org/10.1186/1471-2164-11-726

Wasteneys, G. O., \& Galway, M. E. (2003). Remodeling the cytoskeleton for growth and form: an overview with some new views. Annu Rev Plant Biol, 54, 691-722. http//dx.doi.org/10.1146/annurev.arplant.54.031902.134818

Wehmeyer, N., Hernandez, L. D., Finkelstein, R. R., \& Vierling, E. (1996). Synthesis of small heat-shock proteins is part of the developmental program of late seed maturation. Plant Physiol, 112, 747-757. http://dx.doi.org/10.1104/pp.112.2.747

Wei, X., Xu, J., Guo, H., Jiang, L., Chen, S., Yu, C., ... Wan, J. (2010). DTH8 Suppresses Flowering in Rice, Influencing Plant Height and Yield Potential Simultaneously. Plant Physiol, 153, 1747-1758. http://dx.doi.org/10.1104/pp.110.156943

Wilson, I. D., Barker, G. L. A., Lu, C., Coghill, J. A., Beswick, R. W., Lenton, J. R., \& Edwards, K. J. (2005). Alteration of the embryo transcriptome of hexaploid winter wheat (Triticum aestivum cv. Mercia) during maturation and germination. Funct Integr Genomics, 5, 144-154. http//dx.doi.org/10.1007/s10142-005-0137-2

Yamazaki, H., Nishijima, T., Yamato, Y., Koshioka, M., \& Miura, H. (1999). Involvement of abscisic acid (ABA) in bulb dormancy of Allium wakegi Araki I. Endogenous levels of ABA in relation to bulb dormancy and effects of exogenous ABA and fluridone. Plant Growth Regul, 29, 189-194. http//dx.doi.org/10.1023/A:1006212427997

Yang, S. S., Tu, Z. J., Cheung, F., Xu, W. W., Lamb, J. F., Jung, H. J. G., Vance, C. P., \& Gronwald, J. W. (2011). Using RNA-Seq for gene identification, polymorphism detection and transcript profiling in two alfalfa genotypes with divergent cell wall composition in stems. BMC Genomics, 12, 199. http//dx.doi.org/10.1186/1471-2164-12-199 
Yant, L., Mathieu, J., \& Schmid, M. (2009). Just say no: floral repressors help Arabidopsis bide the time. Curr Opin Plant Biol, 12, 580-586. http://dx.doi.org/10.1016/j.pbi.2009.07.006

Zhang, H., Sreenivasulu, N., Weschke, W., Stein, N., Rudd, S., Radchuk, V., P... Graner, A. (2004). Large-scale analysis of the barley transcriptome based on expressed sequence tags. Plant J., 40, $276-290$. http//dx.doi.org/ 10.1111/j.1365-313X.2004.02209.x

\section{Copyrights}

Copyright for this article is retained by the author(s), with first publication rights granted to the journal.

This is an open-access article distributed under the terms and conditions of the Creative Commons Attribution license (http://creativecommons.org/licenses/by/3.0/). 